\title{
OLHARES TRANÇADOS: ALGUMAS QUESTÕES SOBRE A UTILIZAÇÃO DO VÍDEO EM PROJETOS COLETIVOS
}

\author{
Andréa Borghi Moreira Jacinto ${ }^{1}$
}

O presente artigo trata da utilização do vídeo e da construção de sentidos em projetos coletivos de pesquisa, guiados por referências da antropologia visual, e envolvendo diferentes grupos étnicos e sociais, bem como pesquisadores e estudantes de perspectivas disciplinares diversas. Serão descritas produções audiovisuais de quatro projetos, desenvolvidos na região amazônica, e entre instituições de ensino e pesquisa do norte do Brasil. Articulada a essa proposta, o texto oferece também uma notícia sobre a produção do Núcleo de Imagem, Direito e Meio Ambiente (NIDMA), vinculado ao Programa de Pós-graduação em Direito Ambiental (PPGDA), Universidade do Estado do Amazonas (UEA), e que esteve em operação entre 2005 e $2012^{2}$.

Entre os pontos levantados, discute-se sobre a origem dos projetos, condições técnicas, de produção e participação no processo de filmagem e edição; e a construção de representações e discursos ao longo dos trabalhos. Como os sentidos e as potenciais utilizações dos vídeos são negociados entre diferentes grupos disciplinares e sociais envolvidos em cada trabalho? Como as possibilidades e limites técnicos direcionam e/ou condicionam o que é selecionado e enfocado nos registros e edição dos materiais? Qual o lugar da antropologia, entre as diferentes abordagens acionadas, processos e construções de sentidos? Tais questões serão levantadas principalmente a partir dos documentários "O saber que a gente sabe - diálogos entre conhecimentos tradicionais e científicos na Amazônia"(2006, 26 min.); "Sob as Águas - Acordos de Sobrevivência"(2009, 18 min.); das realizações em audiovisual do projeto Murawara (2007-2008 UEA/FAPEAM); do documentário "Bora, gente! Direitos e conhecimentos em Movimento" (2011, $42 \mathrm{~min})$.

\footnotetext{
${ }^{1}$ Instituto de Educação Superior de Brasília, Brasil.

${ }^{2}$ Uma versão preliminar deste trabalho foi apresentada na III Reunião Equatorial de Antropologia (REA)/ XII Encontro de Antropólogos Norte e Nordeste (ABANNE). Boa Vista, Roraima. 14 a 17 de agosto de 2011. GT 24 - Imagens sobre a Amazônia - Um olhar a partir da Antropologia Visual. Coordenadores: Renato Athias (UFPE) e Gabriel O. Alvarez (UFG).
} 


\section{Produção Audiovisual e Núcleos de Pesquisa: algumas de notícias do Norte}

A produção audiovisual associada à pesquisa científica, e a reflexão sobre seus limites e condições são temas amplas. Nas três últimas décadas, com os avanços das tecnologias audiovisuais como o vídeo e as mídias digitais, tal discussão ganhou maior visibilidade em várias áreas do conhecimento, ampliando-se o campo dos 'documentários científicos'. No campo das ciências sociais, particularmente da antropologia, observa-se nas universidades brasileiras, a partir da década de 80, a criação de núcleos voltados ao uso da imagem (cinema, vídeo, fotografia) na pesquisa e na criação de documentação audiovisual (Monte-Mor, 1999; Eckert et al, 1995). Também nas ciências naturais, como a física, o vídeo tem sido usado na produção e divulgação de filmes científicos - levando, por exemplo, à estruturação do Laboratório de Criação Visual, do Departamento de Física da Universidade Estadual de Maringá (Rohling et al., 2002). No âmbito do direito - campo ao qual as produções aqui descritas também se relacionam mais diretamente - pode-se mencionar o projeto 'O Direito Achado na Rua', surgido com o grupo ligado à Nova Escola Jurídica e a Roberto Lyra Filho, tendo como desdobramento a produção de vídeo-documentário com o mesmo nome, a partir do argumento de José Geraldo de Souza (1992). Esse filme e outros ligados a temas do direito e política foram produzidos pelo Centro de Produção Cultural e Educativa (CPCE), da Universidade de Brasília ${ }^{3}$.

No caso particular do Amazonas, segundo Costa \& Lobo (2005), teríamos uma história do cinema muito mais marcada pelo documental que o ficcional, tendo como grande precursor os trabalhos de Silvino Santos, nas primeiras décadas do século XX. Paradoxalmente, embora essa história comece em 1897, com a primeira exibição de cinema em Manaus e tenha, em mais de cem anos, forte vínculo com o cinema documental, Costa \& Lobo apontam a descontinuidade com uma das marcas dessa história. Os autores observam o fato de que a produção sobre a região amazônica tenha feito "mais por encobrir que revelar a realidade amazônica", recriando-se os “mais desvairados mitos sobre a região" (: 297).

O incentivo à produção audiovisual e seu intercâmbio com o universo científico pode ser uma forma de se desconstruir esses mitos, apostando-se em modos diversos de registro, representação e documentação da e sobre a região amazônica. Nesse sentido, são referenciais as realizações do Núcleo de Antropologia

\footnotetext{
${ }^{3}$ Sobre o CPCE/Unb, ver: http://www.cpce.unb.br/index.html.
} 
Visual/NAVI da Universidade Federal do Amazonas, coordenado por Selda Vale. O NAVI conseguiu consolidar a Mostra Amazônica do Filme Etnográfico, em sua $5^{\mathrm{a}}$ edição em 2011, exibindo e reunindo um conjunto significativo de documentários sobre a Amazônia e produzidos na Amazônia, bem como estimulando a produção e formação em suas várias atividades. ${ }^{4}$.

Essas experiências foram importantes e nortearam a criação do Núcleo de Imagem, Direito e Meio Ambiente (NIDMA-PPGDA/UEA), que entre 2005 e 2012 buscou investir em caminhos de formação do olhar e de produção de documentários ligados à pesquisa acadêmica (Jacinto, 2008) ${ }^{5}$. A intenção desse texto, além de dar notícia sobre a produção que será descrita a seguir, reforça também seus vínculos com os princípios do filme etnográfico e da antropologia visual (Ribeiro, 2007). I

Se as produções que serão descritas são fortemente marcadas por relações interdisciplinares; os produtos audiovisuais podem ser lidos igualmente de diferentes modos: canal de mediação entre sujeitos sociais; experiência artística, instrumentos de auto-representação; de registro e representação de conflitos, grupos e fenômenos sociais; instrumentos de comunicação e reflexão. Experiências e registros que, junto a esse entrelaçamento de referências, compartilham alguns dos que seriam os princípios fundamentais do cinema etnográfico. Segundo Ribeiro, embora os métodos do cinema etnográfico sejam variados e relacionados a diferentes tradições teóricas, meios e procedimentos utilizados, alguns elementos parecem configurar princípios fundamentais:

(...) uma longa inserção no terreno ou meio estudado freqüentemente participante ou participada; uma atitude não diretiva fundada na confiança recíproca valorizando as falas das pessoas envolvidas na pesquisa; uma preocupação descritiva baseada na observação e escuta aprofundadas independentemente da explicação das funções, estruturas, valores e significados do que descrevem; utilização privilegiada da música e sonoridades locais na composição da banca sonora.

(Ribeiro, 2007: 7-8)

As descrições seguintes oferecem elementos para essas, entre outras questões possíveis, considerando também o retorno das produções aos grupos envolvidos. Tenta-se observar igualmente, ao longo das descrições, a contribuição que a

\footnotetext{
${ }^{4}$ A respeito do NAVI, e da Mostra Amazônica do Filme Etnográfico, ver http://www.navi.ufam.edu.br/ ${ }^{5}$ A criação do Núcleo/NIDMA em 2005 foi iniciativa de Fernando Antonio de Carvalho Dantas, então coordenador do Programa de Pós-graduação em Direito Ambiental (PPGDA). A idéia surgiu após uma primeira experiência no campo de produção audiovisual, o filme "Direito, Sociobiodiversidade e Soberania na Amazônia" (2005, 10 min.). A respeito, consultar:
} 
antropologia pôde oferecer à produção audiovisual em campos de ação interdisciplinar, em projetos coletivos, e na relação entre diferentes grupos sociais.

\section{O Saber que a Gente Sabe - diálogos entre conhecimentos tradicionais e científicos na Amazônia}

Finalizado em 2006, o documentário "O saber que a gente sabe" (26 min.) pretendeu discutir visões relativas ao tema dos conhecimentos tradicionais e sua proteção jurídica ${ }^{6}$. Sua proposta foi a de promover um diálogo entre sujeitos que representassem diferentes modos de pensar os saberes e conhecimentos tradicionais, e também entre sujeitos sociais produtores desses conhecimentos, particularmente os relativos à cura por meio de plantas. Os personagens do filme são ligados a diferentes posições, tradições e interesses em campos de conhecimentos que envolvem plantas medicinais, como cientistas, raizeiros, benzedores, pais de santo, comerciantes e também juristas. A idéia do vídeo, mais do que fechar de antemão uma posição sobre a discussão, era a de levantar os nós e dilemas do tema da proteção jurídica aos conhecimentos tradicionais, construídos a partir dos depoimentos.

Nesse sentido, a realização do filme foi também uma espécie de laboratório para a equipe que o concebeu e realizou; uma experiência interdisciplinar que reuniu dois juristas, uma antropóloga, uma química e um cineasta em torno desse objeto, além de outras pessoas de diferentes áreas que contribuíram para sua realização ${ }^{7}$. O fato de nos situarmos em campos disciplinares distintos, permeados por desdobramentos políticos e ideológicos, não obstante a amizade, afinidades e objetivos comuns que partilhávamos, fez com que tivéssemos de enfrentar, na concepção e produção do trabalho, alguns dos dilemas e conflitos relativos à proteção jurídica do conhecimento tradicional ${ }^{8}$.

\footnotetext{
${ }^{6}$ O saber que a gente sabe - Diálogos entre conhecimentos tradicionais e científicos na Amazônia (28 min./ 2006).. Direção Andréa Borghi M. Jacinto, Cristiane Derani, Homero Flávio. Programa de Pósgraduação em Direito Ambiental - UEA.

${ }^{7} \mathrm{O}$ argumento foi desenvolvido por Cristiane Derani, Fernando Antonio de Carvalho Dantas, Sandra Zanotto, Homero Flávio e por mim. Esse grupo se dividiu também entre diferentes frentes do projeto, entre produção, filmagens, edição e lançamento.

${ }^{8}$ Edgar Morin $(1980,32)$ traz um caso interessante sobre a "colaboração conflituosa" durante a escrita de $O$ Método: "Tive como colaborador, ou antes como interlocutor principal, John Stewart, biólogo que até então se consagrara principalmente à genética das populações. (...) Já não sei muito bem quais foram as idéias que me inspirou, e que tendo egocentricamente a considerar como minhas (...), mas sei que a sua contribuição fundamental foi crítica, sobretudo quando se irritou e me fez irritar contra ele. Operou-se assim uma estranha e imprevista cooperação conflituosa ou colaboração antagonista desde ele até mim. Ele, biólogo desanimado, dirigia-se à sociologia e para essa redução a esquemas políticosociais que erroneamente costumam identificar com o marxixmo; eu, sociólogo desanimado, dirigia-me
} 
Além de evidenciar perspectivas divergentes e tensões no interior da equipe, a inserção em campos disciplinares diversos por outro lado ampliou as redes alcançadas pelo filme. Esse aspecto foi essencial pelo menos em dois pontos. Primeiro, cada um de nós, justamente por essa inserção, pode acionar com mais facilidade determinados sujeitos/personagens buscados pelo trabalho, além de poder estabelecer uma comunicação ou empatia com esses sujeitos, já compartilhando ou conhecendo algumas de suas posições ou dificuldades em relação ao tema.

Esses vínculos também foram importantes na construção dos compromissos entre equipe e os participantes/personagens. Em situações de convívio e registros mais longos, tentamos marcar com os próprios depoentes o que poderia ser registrado e/ou reproduzido, e o que seria partilhado como comunicação informal. Houve também situações em que a própria equipe avaliou a pertinência, segurança e ética de se utilizar ou não de depoimentos ou imagens que poderiam comprometer, de alguma forma, os entrevistados. Do ponto de vista formal e de procedimentos, antes de qualquer filmagem, o projeto e seus propósitos eram apresentados. Ao final do depoimento, pedíamos que o entrevistado fizesse a declaração oral, registrada em vídeo, autorizando a utilização das imagens para o documentário, com fins educativos e não comerciais. Na época, tínhamos a intenção, além de guardar essas autorizações em vídeo, de editar um 'extra/bonus' do documentário, produzindo um filme de um minuto chamado "Com sentimento", com a seleção de algumas das autorizações colhidas.

Outro aspecto relativo aos diferentes campos de origem disciplinar e de atuação da equipe remete às condições de produção e realização do filme. Em se tratando de uma produção de baixo custo, exercida em vários momentos por voluntarismo, essa ampliação das redes e a solidariedade nela encontrada foram essenciais para a execução do projeto. Conseguimos, por esse meio, realizar filmagens em diferentes lugares do Amazonas, no Pará, no Distrito Federal, no Acre e no Paraná ${ }^{9}$.

não apenas para a biologia, mas também para a physis; ele tendia para o sociocentrismo, eu para o fisiocentrismo.".

${ }^{9}$ Assim, nas filmagens em Brasília, junto ao CGEN, foram fundamentais o apoio técnico e logístico de Leslye Bombonatto Ursini e Ricardo Calaça (Olhar Etnográfico), antropólogos com experiência no campo audiovisual e no debate sobre conhecimentos tradicionais. Em Curitiba, para a entrevista com Carlos Frederico Marés, José Peres Gediel e Paulo Pankararu, o apoio técnico de Fernando Marés de Souza e Francisco Marés também foi fundamental.Todas essas situações foram acompanhadas de, pelos menos, um dos responsáveis pelo argumento do filme. 
A edição também ocorreu como um processo coletivo - o que não tornou as coisas mais fáceis. O processou durou cerca de duas semanas, de modo intensivo ${ }^{10}$. Nesse período, intercalamos a decupagem do material bruto (cerca de 20 horas), assistimos documentários que ofereceram referências audiovisuais comuns ao grupo $^{11}$, e tivemos mais presentes os músicos que assinam a trilha sonora ${ }^{12}$. Aos poucos, e nesse processo, é que fomos encontrando o fio do filme.

Uma motivação comum, que nos moveu entre os entraves, foi certamente o prazo e o compromisso construído, entre participantes, depoentes e instituições, para a exibição pública do filme na $8^{\mathrm{a}}$. Reunião das Partes da Convenção da Diversidade Biológica, ocorrida em 2006, em Curitiba.

De lá para cá, o documentário pode fazer sua própria história. Em relação ao retorno aos participantes, uma primeira ação foi a realização de um evento público de lançamento/exibição em Manaus, ao qual foram convidados os participantes que residiam na cidade ou em sua proximidade. Iniciamos, também, a entrega de exemplares do DVD para os participantes e instituições envolvidos. Essa entrega não aconteceu de modo sistemático, inclusive por falta de recurso na época da conclusão do filme. De certo modo, tivemos aqui um desdobramento das situações propiciadas pelas redes e oportunidades: alguns receberam pelo correio, de modo formal; outros receberam visitas em suas casas - ou no terreiro, ou no mercado, para a entrega do documentário; outros tiveram acesso ao material quando um evento propiciou o encontro com um membro da equipe; ou seja, o retorno via entrega do DVD foi sendo realizada ao longo do tempo em reencontros com os participantes e membros da equipe.

Essa devolução pessoal ou institucional remete, no entanto, a uma forma de retorno possível. O principal compromisso do filme era o de divulgar e estimular um debate sobre a regulação jurídica dos conhecimentos tradicionais associados ao patrimônio genético. Nesse sentido, a veiculação do filme nos últimos seis anos, em mostras, eventos, cursos e outras situações públicas e propícias ao debate configuram, provavelmente, o principal retorno que o projeto pode oferecer aos grupos envolvidos.

\footnotetext{
${ }^{10}$ Michel Ferreira de Oliveira editou o material, e Homero Flávio, Sandra Zanotto e eu enfrentamos a 'montagem', desenhando o roteiro da edição e a seleção das imagens e depoimentos.

${ }^{11}$ Como Iracema: Uma Transa Amazônica (90min). Dir. Jorge Bodanski e Orlando Senna. Brasil/ Alemanha, 1974, 91 min.; e Janela da Alma, Dir. João Jardim e Walter Carvalho, Brasil, 2002, 73 min. ${ }^{12}$ Leonardo Jaques e Leonardo Pimentel foram responsáveis pelas composições originais, e pela seleção musical.
} 


\section{Murawara - lembranças de uma pesquisa}

O segundo conjunto de produções audiovisuais aqui comentadas foi produzido no âmbito do projeto "Murawara: Memórias do Povo Mura no Municípo de Itacoatiara'. implementado entre 2007 e 2008, a partir de uma demanda indígena, e que tinha com núcleo central de sua equipe jovens estudantes e uma professora, todos indígenas, residentes nas Terras Indígenas Rio Urubu e Paranã do Araotó, no município de Itacoatiara, no estado do Amazonas ${ }^{13}$.

Durante cerca de seis meses, os jovens indígenas realizaram o objetivo do projeto: desenvolver pesquisa sobre a memória dos Mura na região. Ao tentar oferecer aos jovens pesquisadores condições de pesquisa e registro da memória, principalmente dos mais velhos, foram realizados treinamentos sobre pesquisa de campo, a partir do referencial da antropologia, e sobre a utilização de recursos audiovisuais nesse registro, exercício de ouvir e contar: gravadores digitais, câmeras fotográficas, e filmadora (Mini-dv).

Pelos breves treinamentos que tiveram, muito do que aprenderam em relação aos equipamentos foi resultado da prática de pesquisa que desenvolveram - como o entendimento, inclusive, de que há momentos em que nada se liga; antes se conversa, se espera, se conhece. E o fato de serem indígenas não necessariamente facilitou para eles a "abertura do campo"; como quaisquer outros pesquisadores, tiveram também que se fazer explicar, evidenciar objetivos do projeto, dos ganhos ou interesse para a comunidade ou para um possível entrevistado, e tiveram que lidar com algumas negativas e recusas de outros Mura em relação ao trabalho que desenvolviam.

Além da questão do manuseio, o uso dos equipamentos audiovisuais envolveu uma preocupação, muitas vezes reforçada pelos representantes da Organização das Mulheres Indígenas do Rio Urubu (OMIMRU) e da Fundação Estadual dos Povos Indígenas (FEPI), parceiros do projeto: o de que se tratava de um material do projeto e da universidade, e que não deveria ser usado ou apropriado de modo pessoal. Tal posição foi reforçada não só entre a equipe do projeto e as instituições envolvidas,

\footnotetext{
${ }^{13} \mathrm{O}$ Projeto foi idealizado a partir da demanda apresentada pela Organização das Mulheres Indígenas Mura do Rio Urubu (OMIMRU), articulada institucionalmente pela Fundação Estadual dos Povos Indígenas (FEPI), contando com o financiamento da Fundação de Amparo à Pesquisa do Estado do Amazonas (FAPEAM). Além dos pesquisadores indígenas, a equipe era formada por uma antropóloga (coordenação), um cientista social e uma estudante de direito, além de vários colaboradores. Para mais detalhes, ver Jacinto, Andréa Borghi M. "Murawara: sobre a pesquisa de jovens cientistas indígenas". Trabalho apresentado na II Reunião Equatorial de Antropologia (REA)/ XI Reunião de Antropólogos do Norte e Nordeste (ABANNE), no GT 01 Educação Escolar e Povos Indígenas. Disponível em: http://www.www.cchla.ufrn.br/REA2009/?pg=publi .
} 
mas também nos encontros comunitários em que o mesmo era discutido, sendo um tema delicado e ao qual a maioria das pessoas era bastante sensível ${ }^{14}$.

Esse cuidado material parece ter gerado um outro dilema entre a equipe indígena. Várias vezes, como coordenadora do projeto, ouvi justificativas ou uma espécie de pedido de desculpas por situações registradas que eram importantes para os próprios jovens pesquisadores: um jogo do torneio de futebol, uma festa de aniversário, a fala de um pastor, uma foto entre amigas do colégio. Como antropóloga, julgava interessante e ricas as possibilidades abertas por esses registro do cotidiano da aldeia e de suas vidas; porém os jovens indígenas traziam em sua justificativa a marca de um interesse pessoal nesse uso, e não imaginavam outra utilização ou interesse sobre as imagens. O ponto delicado dessa situação esteve talvez no limite pouco nítido entre a apropriação material de um equipamento 'do projeto', ou seu uso para um propósito pessoal, e a representação ou autorepresentação envolvidas, uma vez que, como jovens Mura, eles participavam como sujeitos e objetos da pesquisa, pessoal e público.

De fato, essa dupla participação dos jovens indígenas, como pesquisadores e sujeitos do universo pesquisado, foi também motivo de dúvida para o Comitê de Ética da UEA que julgou a proposta do projeto e seu pedido de autorização para a pesquisa. Em função do próprio contexto de criação dos comitês de ética no Brasil, a composição do comitê era basicamente formada por pesquisadores da área de biomédicas, que tinham pouco ou nenhum contato com pesquisa na área de ciências sociais e antropologia. O projeto Murawara foi o primeiro projeto, envolvendo povos indígenas, a ser julgado, e seu processo teve muitas idas e vindas até que se entendesse a inadequação dos formulários institucionais para a descrição desse tipo de pesquisa envolvendo seres humanos, indígenas Mura, eles próprios pesquisadores e sujeitos da investigação sobre a memória Mura na região de Itacoatiara, Amazonas.

As possibilidades de auto-representação parecem ter tido relação também com o interesse pelo material bruto, como apontado em outros contextos de produção audiovisual indígena pelo Mostra Vídeo nas Aldeias ${ }^{15}$. Realizamos em Manaus, em três ocasiões distintas, oficinas para acompanhamento da pesquisa e tratamento dos materiais registrados (áudio, fotos e vídeos), onde analisamos em conjunto as

\footnotetext{
${ }^{14} \mathrm{O}$ projeto teve seu início logo após um período de conflitos internos envolvendo a OMIMRU e lideranças Mura de diferentes aldeias; relacionados também a gestão de recursos obtidos pela Organização.

${ }^{15}$ Ver, por exemplo, em "Conversa a cinco", in Escorel; Coutinho; Corrêa; Bloch; Carelli (2006).
} 
imagens, áudios e transcrição das entrevistas e imagens, discutindo o tratamento e possibilidades abertas por esses materiais. Durante essas ocasiões, a oportunidade de se ver e de ver os conhecidos, pareceu ser sempre um dos momentos de mais curiosidade e prazer durante o trabalho. $\mathrm{O}$ material bruto foi ainda uma chance de se guardar imagens de saudade: algum tempo depois do término do projeto, uma das jovens pesquisadoras perdeu seu filhinho de dois anos. As imagens que fez de um dia em que saía de sua casa flutuante para visitar em pesquisa outra aldeia, são as únicas, além daquelas da memória, que pôde guardar de seu menino.

Ao término do projeto, o resultado imediato que os participantes, grupos e instituições envolvidas receberam foi principalmente textual: a coletânea das entrevistas realizadas, editadas com algumas das fotos feitas pelos pesquisadores Mura $^{16}$. Todos os jovens pesquisadores receberam também cópias em DVD, das fotos e do material bruto registrado em vídeo. Tínhamos em mente a idéia de editar um filme com os registros feitos pelos pesquisadores Mura. Ainda durante as oficinas do projeto, conseguimos fazer alguma discussão sobre as imagens com a equipe, uma espécie de seleção temática. Porém, nesse projeto, a edição do filme foi um processo mais difícil e segmentado. Uma primeira tentativa ocorreu no final de 2008, no fim do projeto; mas não conseguimos finalizar o filme para o evento que ocorreu na Aldeia Unidos do Cana, quando entregamos publicamente a coletânea das entrevistas. Somente em 2009, consegui um novo recurso para resolver os problemas de edição que permaneciam, mas mesmo assim, o material ficou com algumas pendências, e guardado por dois anos em uma 'gaveta'. Em parte, acredito que essa dificuldade ocorreu também em função do perfil de editores com os quais trabalhamos nesse caso; ambos com experiência maior no campo de TV, o que dispõe um manuseio particular dos tempos e ritmos, de opções estéticas e de relação com o material, às vezes difíceis de serem articulados às razões do documentário e do filme etnográfico.

Ao final de 2011, foi criado um blog do Núcleo de Imagem, Direito e Meio Ambiente, com o objetivo de registrar e disponibilizar algumas de suas produções ${ }^{17}$. Uma das páginas construídas reúne as produções feitas no Murawara, entre elas, a publicação com as entrevistas e pesquisa dos jovens cientistas; uma seleção de fotos que realizaram; e um link para o filme "Murawara - lembranças de uma

\footnotetext{
${ }^{16}$ O material foi publicado em 2010, como número especial da Hiléia - Revista de Direito Ambiental na Amazônia. Dossiê Mura. Ano 6, no. 10. Programa de pós-graduação em Direito Ambiental, Universidade do Estado do Amazonas. UEA - Edições do Governo do Estado do Amazonas, 2008.

${ }^{17}$ Conferir em: http://www.nucleodeimagem.blogspot.com.br .
} 
pesquisa"(2009, 11 minutos), também disponível no youtube $e^{18}$. Sobre a repercussão ou desdobramentos dessa veiculação, ainda não há notícias mais consistentes. Mas, as ferramentas virtuais são, sem dúvida, uma nova e rica possibilidade de partilhar os olhares trançados e construídos, sobretudo pelos jovens cientistas: Iriane, Rosenilson, Mara, Izomar, Elia, e a professora Mura Roselane Bruno, que dirigiu o registro das imagens em Terras Mura.

\section{Sob as Águas - Acordos de Sobrevivência}

A terceira experiência coletiva de produção audiovisual refere-se ao documentário "Sob as Águas - acordos de Sobrevivência" (2009, 18 min.), que surgiu no contexto de dois projetos de pesquisa nos campos de direito e ecologia de pesca, coordenados por Serguei Aily Franco de Camargo ${ }^{19}$,que propôs ao Núcleo a realização do filme. O filme trata dos acordos de pesca e conflitos em torno dos recursos pesqueiros na Região Amazônica, principalmente na região de Boa Vista do Ramos (AM). Traz depoimentos de pescadores, entre os chamados artesanais e comerciais, representantes de Colônias de Pescador e Sindicato do Trabalhadores da Pesca, do IBAMA, de pesquisadores da Pesca na Amazônia, e registros de algumas reuniões em torno de um acordo de pesca, acompanhado por pesquisadores dos projetos mencionados.

Foi formada uma equipe primeira, entre participantes dos projetos e colaboradores da área audiovisual; mas dessa vez, diferentemente das duas outras experiências, tentando-se definir melhor funções/papéis no campo audiovisual antes de iniciar as primeiras filmagens, na região de Boa Vista do Ramos, Rio Urubu. Depois, nas filmagens em Manaus e durante a edição, houve uma redefinição na equipe, inclusive nas áreas mais técnicas de câmera e edição ${ }^{20}$. Em relação às duas outras experiências, talvez esse tenha tido mais presença de alunos do PPGDA, por duas razões. Primeiro, pelos projetos de pesquisa ao que estava vinculado, com ênfase em atividades de campo, na região de Boa Vista do Ramos. Segundo, porque

\footnotetext{
${ }^{18}$ Disponível em: http://www.youtube.com/watch?v=1sJ2IrCqDR4.

19 "Direito Pesqueiro na Bacia Amazônica"/CT Amazônia (CNPq); “Gestão Participativa da Pesca na região do Rio Urubu no município de Boa Vista do Ramos” (FAPEAM).

${ }^{20}$ Ficha Técnica - Direção e Roteiro: Serguei Aily Franco de Camargo e Andréa Borghi M. Jacinto Edição e Finalização: Eddie Souza Imagens: Antonio Sena, Eddie Souza, Erasmo Assunção, Homero Flávio, Inimar Bitto, Serguei Camargo, Thaísa Lustosa de Camargo Trilha Sonora Original: Léo Cólera Pesquisa: Serguei A. F. de Camargo, Regina G. Pinheiro Cerdeira, Erasmo Whelmes do N. Assunção; Everaldo M. Amoedo; Alzenilson S. de Aquino, Márcio Bentes Lima.
} 
conseguimos realizar praticamente todo o processo de edição no espaço do PPGDA/UEA, na ilha montada na sala do Núcleo de Imagem, Direito e Meio Ambiente $^{21}$. Essa condição física facilitou a presença dos alunos, em vários momentos, do tratamento e discussão sobre o material bruto, da decupagem, à edição e lançamento do filme.

Em relação aos retornos a grupos e instituições envolvidas, deve-se mencionar que já havia antes da produção do documentário, um processo colaborativo entre projeto e comunidade, onde a equipe coordenada por Camargo auxiliou e acompanhou a comunidade na elaboração de um acordo de pesca. Em relação ao filme, além da entrega de DVDs a depoentes, foi feita uma exibição pública em uma das comunidades ribeirinhas de Boa Vista do Ramos, e também um evento de lançamento do documentário em Manaus.

\section{Bora, Gente! Direitos e Conhecimentos em Movimento}

A última realização audiovisual produzida pelo NIDMA/UEA envolveu a produção do documentário "Bora, gente! Direitos e Conhecimentos em Movimento" (Manaus, 2011, 42 min.). Percorrendo regiões do Maranhão e do Pará, o filme visita o Povo Tembé, as Quebradeiras de Coco Babaçu e os Tiradores de Açaí, observando entre seus contextos particulares, algumas experiências comuns nos desafios e pressões sofridas sobre modos de vida e territórios. O documentário oferece um vislumbre sobre suas histórias de organização e mobilização política, bem como de suas experiências de contato e relação com o Estado, o direito e o mercado. Traz também algo de suas visões sobre conhecimento e ciência, sobretudo a partir das relações construídas com três jovens pesquisadores, mestrandos das universidades e instituições de pesquisa envolvidas na produção do documentário.

Financiado pelo Programa Procultura (MinC/CAPES),o filme foi realizado por meio da colaboração entre diferentes instituições e organizações: Universidade Federal do Pará (UFPA), Universidade do Estado do Amazonas (UEA), Movimento Interestadual das Quebradeiras de Coco Babaçu (MIQCB), Empresa Brasileira de Pesquisas Agropecuárias (EMBRAPA), Museu Paraense Emílio Goeldi (MPEG) e Associação em Áreas de Assentamento no Estado do Maranhão (ASSEMA),

\footnotetext{
${ }^{21}$ Montamos uma ilha de edição, e adquirimos um boa câmera, microfones e tripé por meio do projeto “Consolidação do Núcleo de Imagem, Direito e Meio Ambiente”(FAPEAM, 2007-2008).
} 
articuladas ao projeto "A Cultura na Construção e Defesa dos Territórios Tradicionais: Legislação e Políticas Publicas para a Proteção dos Conhecimentos Tradicionais numa Sociedade Pluriétnica" ${ }^{22}$. Seu processo de produção e realização envolveu uma equipe diversa, entre pesquisadores de diferentes áreas(antropologia, direito, agronomia, geografia, engenharia floresta, entre outros), profissionais do audiovisual, integrantes de movimentos sociais, e colaboradores - juntos na utilização da arte e da linguagem audiovisual como instrumento de produção de conhecimentos e comunicação ${ }^{23}$

O projeto propôs entre seus objetivos, documentar e divulgar suas experiências de pesquisa sobre o tema dos conhecimentos tradicionais, e questões de direito, identidade e território por meio não só da linguagem científica e acadêmica, mas também pela linguagem musical e audiovisual. Responsáveis no projeto por essa incursão pela música foram as “As Encantadeiras”, grupo musical de quebradeiras de coco babaçu dos Estados do Piauí, Maranhão e Tocantins, integradas ao Movimento das Mulheres Quebradeiras de Coco Babauçu (MIQCB). O exercício do audiovisual ficou a cargo do Núcleo/ NIDMA, sendo proposto em duas frentes: a) documentação/ registro de atividades do projeto, como as oficinas de trabalho e pesquisas de campo; b) lançamento de produto áudio visual, a ser apresentado à Comissão Nacional dos Povos e Comunidades Tradicionais e ao MINC para divulgação e disseminação, que se tornou o "Bora, gente!".

A interação da rede envolvida pelo projeto na linguagem audiovisual ocorreu de diferentes modos, e principalmente em tempos de reuniões e oficinas da equipe. Em 2010 (abril/maio), ocorreram a 1ª. Oficina de pesquisaem São Luis do Maranhão; pesquisa de campo entre as quebradeiras (Lago do Junco e Pedreira/MA) e ainda um

\footnotetext{
${ }^{22}$ Edital no. 07/2008 CAPES/MINC Programa Procultura. O projeto tem como instituição líder a Universidade Federal do Pará (UFPA), tendo como coordenadora geral a antropóloga Noemi Sakiara Miyasaka Porro.

${ }^{23}$ Ficha Técnica. Direção: Andréa Borghi M. Jacinto e Eddie Souza Jr Imagens e Fotografia: Eddie Souza Jr. Roteiro: Andréa Borghi M.Jacinto/ Joaquim Shiraishi Neto/André Marques.Edição: André Marques Edição de Áudio: Léo Cólera. Projeto: “A Cultura na Construção e Defesa dos Territórios Tradicionais: Legislação e Políticas Publicas para a Proteção dos Conhecimentos Tradicionais numa Sociedade Pluriétnica". Coordenação Geral: Noemi Sakiara Miyasaka Porro

Produção e Pesquisa junto ao povo Tembé do Gurupi e Tembé do Guamá: Claudia López, Lena Claudia Amorin Saraiva, Vanderlúcia Ponte, Ana Dayse Amaral

Produção e Pesquisa junto às quebradeiras de coco babaçu, nos municípios de Esperantinópolis $e$ Lago do Junco: Joaquim Shiraishi Neto, Luciano Maciel, Maria Alaídes, Silvanete Matos, Manoel Rodrigues, Alex Torres, Sheilla Borges Dourado

Produção e Pesquisa junto aos tiradores de açaí, no município de Afuá: Noemi M. Porro, Maricélia Gonçalves Barbosa, José Amorin Monteiro (Trevoada)

Produção e Pesquisa em Belém (entrevistas com as Encantadeiras): Iran Veiga, Noemi Porro.

FINANCIAMENTO: Edital Procultura (MinC/CAPES).
} 
encontro de parte do grupo em Manaus, durante o Simpósio Conhecimentos Tradicionais e Territórios na Pan-Amazônia ${ }^{24}$. Entre registros dos eventos e pesquisa de campo nessas situações, foram cerca de dez horas de gravação em vídeo.

Em 2011, o maior mergulho ocorreu entre março e abril, com o registro audiovisual durante a realização da $2^{\mathrm{a}}$. Oficina de pesquisa, em Belém, e na sequiência, com as filmagens realizadas nos contextos das três pesquisas de campo, desenvolvidas pelos mestrandos vinculados ao projeto: entre os Tembé (PA), Quebradeiras de Côco Babaçu (MA), e tiradores de açaí (PA) ${ }^{25}$. Nesse 'mergulho', foram registradas praticamente 20 horas de material, em um esforço que reuniu pesquisadores, o cineasta articulado ao projeto e o apoio de pessoas ligadas aos movimentos sociais e instituições públicas envolvidas.

Essa breve descrição oferece uma visão sobre a complexidade envolvida no projeto, tanto em sua estrutura e rede; em seu tema, quanto pelos sujeitos sociais e contextos de campo envolvidos. Talvez, uma das grandes interferências da linguagem visual na execução do projeto tenha sido, primeiramente, tornar a todos, pesquisadores e participantes, personagens da representação. Com o registro das oficinas, tivemos que nos acostumar com câmera, tripé, microfones convivendo no espaço da organização e realização dos encontros e discussões; e também com o exercício de nos vermos nessas imagens. A partir dos registros em São Luis (2010), todo o material foi decupado, e disponibilizado para os pesquisadores/instituições participantes, que receberam também cópia do material bruto em DVD. Realizamos também um pequeno vídeo experimental, de 10 minutos, que foi exibido durante o Simpósio "Conhecimentos Tradicionais e Territórios na Pan-Amazônia" (Manaus, julho 2010) quando também ocorreu uma apresentação do projeto Procultura, e apresentações musicais das Encantadeiras.

Do ponto de vista da execução e produção audiovisual, tentou-se de diferentes formas integrar ou iniciar os participantes do projeto. Na pesquisa de campo no

\footnotetext{
${ }^{24}$ Promovido pelo Projeto Nova Cartografia Social da Amazônia (PNCSA), ocorrido na Universidade do Estado do Amazonas (UEA), de 14 a 16 de julho de 2010.

${ }^{25}$ Os bolsistas de mestrado, vinculados ao projeto são (na sequência do calendário/itinerário de filmagem): Lena Amorim, "Os Tembé do rio Guamá e do rio Gurupi: Um estudo entográfico do conhecimento tradicionail sobre o território na construção de identidades", Orientadora: Cláudia Lopes, Museu Pararense Emilio Goeldi (MPEG); Luciano Moura Maciel, "As chamadas quebradeiras de coco babaçu e o mercado: dilema entre a proteção do conhecimento tradicional e a sujeição jurídica", Orientador: Joaquim Shiraishi Neto (UEA/PPGDA); e Maricélia Gonçalves Barbosa, "O Ouro preto da Amazônia: relações familiares de trabalho frente a crescente demanda por açai" (UFPA/NEAF), orientada por Noemi Porro.
} 
Maranhão, em março de 2010, a produção de campo foi guiada principalmente por Maria Alaídes, quebradeira de coco babaçu, vinculada ao MICQB e a Associação em Áreas de Assentamento no Estado do Maranhão (ASSEMA), junto a integrantes ${ }^{26}$ do projeto e ao cineasta Eddie Souza. Durante o Simpósio em Manaus, além dos registros e da exibição do filme experimental, fizemos também algumas entrevistas com participantes do Simpósio. Nesse contexto, as quebradeiras de coco Dona Maria de Jesus, conhecida como Dijé, e Maria Alaídes entrevistaram Otávio Velho, vicepresidente da Sociedade Brasileira para o Progresso da Ciência (SBPC) e Deborah Duprat, vice-procuradora-geral da República e coordenadora da 6a . Câmara do Ministério Público Federal (MPF).

Em 2011, durante a última oficina do projeto em Belém, exibimos algumas das imagens registradas em 2010, partilhamos as decupagens do material, e realizamos entrevistas com as Encantadeiras, - que eram participantes do projeto como executoras e, ao mesmo tempo, sujeitos pesquisados. Tentamos também integrar mestrandos e seus respectivos orientadores às atividades de pré-produção das filmagens que seriam realizados nos três campos mencionados, nos Estados do Pará e Maranhão. Esse talvez tenha sido um dos momentos maiores de aprendizado, porque parece ser construída de modo processual a compreensão de que a feitura de um filme envolve mais do que ligar a câmera e, desse modo, pede outras participações além de quem opera o equipamento.

Assim, ainda em Belém, durante o evento e antes da dispersão do grupo, tentamos fechar pré-roteiros de filmagem para cada campo; construir o calendário de cada uma delas; articular uma equipe de apoio em Belém durante a passagem de uma etapa para outra. Tentou-se também reforçar para os mestrandos que, durante as filmagens, sua atuação deveria ir além daquela de pesquisadores; era importante que compreendessem e apoiassem situações ligadas às condições de captação das imagens e áudio, ao transporte dos equipamentos, e do esforço de se criar condições favoráveis às filmagens e ao diálogo com os entrevistados. Mas, claro, o campo é o lugar onde as coisas realmente se definem, inclusive pela interação com aqueles que participam, de um modo ou de outro, das filmagens.

A ligação entre todos os campos - Tembé (PA), Quebradeiras (MA), Tiradores de Açaí (PA) - foi feita, vivencialmente, por Eddie Souza, que atuou nas várias frentes

\footnotetext{
${ }^{26}$ Participaram também desse registro Sheilla Borges Dourado, Luciano Moura Maciel, Alex Torres.
} 
de filmagem: câmera, fotografia, áudio, e fez as vezes de motorista nas estradas escorregadias da região de Paragominas. Nessa região, entre os Tembé do Rio Guamá e do Rio Gurupi, participei das filmagens e da direção do registro. Foi um campo delicado, envolvido por situações tensas de negociação sobre o que fazíamos ali, e sobre o que deveria ser o material que registrávamos. Embora a mestranda que desenvolvia pesquisa entre os Tembé, Lena Amorin, já tivesse feito uma visita prévia, meses antes, relatando às lideranças indígenas sobre a proposta do filme, e providenciando formalmente o consentimento livre, prévio e esclarecido, e outros documentos necessários para filmagem e entrada da equipe em Terra Indígena, quando chegamos, um novo processo se iniciou. As autorizações efetivas se deram nas relações pessoais e de reciprocidade, estabelecida tanto em uma reunião pública, aberta à comunidade da Aldeia Cajueiro, como em cada uma das situações específicas que surgiram na área, entre diferentes aldeias e pessoas.

Ajudou-nos, nesse processo, a exibição do filme Acordos de Pesca, que exibimos na reunião comunitária. O reconhecimento, entre os Tembé do Gurupi, de questões comuns àquela experiência dos pescadores no Amazonas, e a possibilidade vislumbrada de registrarem e discutirem suas próprias questões e problemas deu à equipe a abertura necessária para se começar o trabalho. Outra situação, relativa aos compromissos e autorizações, ocorreu quando visitamos a segunda aldeia na região.

$\mathrm{O}$ roteiro de visitas, as questões a serem tratadas e os possíveis entrevistados tinham sido previamente discutidos e definidos na reunião comunitária. No dia seguinte, seguimos para outra aldeia para entrevistar uma senhora indígena, Dona Brazilice; seu próprio filho, durante a reunião, havia autorizado nossa visita. Fizemos o percurso pelo rio Gurupi, de Voadeira, acompanhandos por dois Tembé. A chegada na aldeia foi registrada pela câmara, que continuou ligada enquanto o restante da equipe se aproximava e se apresentava. Houve certo mal estar e reclamações feitas na língua indígena, e depois traduzidas à equipe, sobre o descontentamento de Dona Brazilice com a câmara e o registro que estava sendo feito. A equipe se desculpou e se justificou comentando a reunião no dia anterior, e os acertos então feitos entre indígenas e equipe de filmagem. Porém, Dona Brazilice deixou claro que se queríamos falar com ela, era ela quem deveria autorizar ou não - ninguém ali poderia decidir por ela. Depois das desculpas aceitas, e do entendimento mútuo sobre o que faríamos ali, tivemos uma linda tarde de conversas, aprendizados, risadas, músicas e histórias. 
No Maranhão, entre as Quebradeiras, e na Ilha do Marajó, entre os Peconheiros, Luciano Maciel e Maricélia Barbosa, respectivamente, acompanharam o trabalho de filmagem com Eddie Souza. Entre as quebradeiras, havia uma maior familiaridade de algumas delas sobre a proposta do filme, além do vínculo formal do projeto com o MIQCB, e também nesse caso houve uma significativa participação nas escolhas sobre temas, questões, lugares e pessoas a serem filmados. No Marajó, entre os tiradores de Açaí, havia também uma experiência já constituída de pesquisa de campo e de trocas, desenvolvida principalmente pelo trabalho da antropóloga Noemi Porro, o que também facilitou o processo de filmagem e a relação com as pessoas entrevistadas.

Boa parte do filme foi musicada a partir das orientações dos próprios grupos envolvidos, fazendo-se a indicação nos créditos das músicas, autorias e participantes da execução. No caso das quebradeiras de coco babaçu, havia o interesse na produção de um registro sonoro das apresentações musicais das Encantadeiras, e durante as filmagens, houve apresentações feitas exclusivamente para o registro audiovisual e sua utilização no vídeo. No caso dos Tembé, aconteceu algo similar. Na visita que fizemos a Dona Brazilice, depois de resolvidos os mal-entendidos, ela e sua família resolveram apresentar, de modo improvisado, algumas músicas e danças sobre os quais havia comentado em seu relato, principalmente relacionados à festa da moça. Quando retornamos a aldeia Cajueiro, nossa base, mostramos algumas das imagens registradas. Isso gerou entre os Tembé o interesse em apresentar as músicas e danças envolvendo a todos da aldeia, de um modo supostamente mais próximo ao que ocorreria nas festas. A apresentação foi feita à noite, em um grande chapéu de palha no centra da aldeia de formato circular; os homens sentados, cantando as músicas, e os jovens, mulheres e crianças executando a dança, criando e desfazendo filas e círculos $^{27}$.

Em relação ao retorno aos grupos envolvidos, um primeiro momento mais amplo, aconteceu no lançamento público do filme, em Brasília, no Auditório da Procuradoria Geral da República. Essa exibição foi um dos momentos do evento de finalização do Projeto, em que se propunha apresentar os resultados dos trabalhos, e promover uma aproximação e debates entre os grupos sociais envolvidos - Tembé, Quebradeiras e Tiradores de Açaí - e instituições públicas - como FUNAI, MMA,

\footnotetext{
${ }^{27}$ A trilha sonora foi editada por Leonardo Jaques (Leo Cólera), que fez também algumas composições originais para o filme.
} 
IPHAN, MDS, MinC, entre outros, em torno da proteção aos conhecimentos tradicionais $^{28}$.

Após essa experiência, foram feitas reproduções do filme em DVD, distribuídos entre as diferentes instituições executoras do projeto, entre pesquisadores, equipe de filmagem, grupos sociais envolvidos, e outras instituições que contribuíram ou atuam em campos relativos aos direitos dos povos indígenas e comunidades tradicionais, principalmente em relação aos seus conhecimentos e territórios. Foram ainda realizados lançamentos públicos do documentário em Manaus e em Belém, e observamos uma apropriação e usos do filme pelas diferentes instituições e grupos envolvidos. Recentemente disponibilizado no youtube ${ }^{29}$, a perspectiva é a de que o filme seja reproduzido de forma livre para fins educativos, culturais e não comerciais, contribuindo ao registro de situações e contextos a ao debate público sobre proteção aos conhecimentos de povos indígenas e comunidades tradicionais.

\section{$* * *$}

Há algum tempo atrás, em uma conversa entre antropólogos, discutia-se o fato de que a produção de documentários não recebe tanta consideração para cálculos de produção intelectual no sistema brasileiro de produção acadêmica. Entre os comentários, foi feita uma piada - talvez um filme não pontue como um artigo, porque pode ser um recurso usado por quem não sabe escrever... A piada, evidentemente, faz graça pelo caricato e exagerado da situação, mas também diz algo sobre uma visão a respeito da linguagem e do discurso audiovisual no universo acadêmico. Leituras e análises de filmes, sejam eles documentais ou ficcionais, podem demonstrar de muitos modos como proposições descritivas, narrativas e conceituais são construídas pela articulação, fragmentação, e duração de imagens e sons no tempo, como fazem tão bem autores Deleuze (1985) e Machado (2008).

No presente artigo, a contribuição que se pretendeu dar remete principalmente a dimensões metodológicas e éticas envolvidas pela pesquisa em sua articulação com o registro e a produção audiovisual. Buscou-se descrever processos de produção e articulação de equipes de pesquisa, em campos interdisciplinares, de redes acionadas

\footnotetext{
${ }^{28}$ Seminário "Proteção ao Conhecimento tradicional: o direito vivido e o direito formal". Promoção: MIQCB; ASSEM; UFPA, UEA, MPEG, EMBRAPA, em 04 de outubro de 2011.

${ }^{29}$ Disponível em: http://www.youtube.com/watch?v=4CVwy aRj30 .
} 
e investigadas, em temas envolvendo direitos de povos indígenas, comunidades tradicionais, ribeirinhos, extratistas ou quebradeiras de coco babaçu, em suas relações com o Estado, com o mercado e outros contextos de relações interétnicas. Com isso, espera-se ter trazido também elementos para a reflexão sobre modos como princípios e referências da antropologia visual têm contribuído às relações interdisciplinares, a produção de conhecimento por meio da linguagem audiovisual, e à interação com sujeitos e grupos sociais - nessa escritura coletiva e de muitas e diferentes etapas que envolve a feitura de um documentário. E sobre o que filmes podem dizer, diferentemente de artigos, a recomendação é só uma: que se assista aos filmes!

\section{Referências}

COSTA, Selda Vale da; LOBO, Narciso Julio Freire. "Cinema no Amazonas". In: Estudos Avançados, v.19, n.53. São Paulo: IEA/ USP, 2005. p. 295-298.

DELEUZE, G. A imagem-movimento. Cinema 1. São Paulo: Brasiliense, 1985. ECKERT, Cornelia et al. "A experiência do Núcleo de Antropologia Visual UFRGS". In: Horizontes Antropológicos, ano1, n.2, jul./set. Porto Alegre: UFRGS, 1995. p. 221-230.

ESCOREL, Eduardo; COUTINHO, Eduardo; CORRÊA, Mari; BLOCH, Sérgio; CARELLI, Vincent. "Conversa a cinco". In: Catálogo da Mostra Vídeo nas Aldeias: um olhar indígena. Olinda: VNA, 2006. p. 34-48.

JACINTO, Andréa Borghi M. "Consolidação do Núcleo de Imagem, Direito e Meio Ambiente". In: Relatório Técnico Final - Programa Primeiros Projetos. Manaus:

FAPEAM; PPGDA/ UEA, 2008.

MACHADO, Arlindo. "O filme-ensaio". In: Intermídias 5 e 6, 2008. Produção independente Revista Intermídias, 2008. Disponível em:

www.intermidias.com/txt/ed56/cinema_0\%20filme-ensaio-Arlindo\%20Machado2.pdf MONTE-MÓR, Patrícia. "Sobre Antropologia e Imagem". In: Boletim da ABA, n.31, $1^{\circ}$. Semestre de 1999. Brasília: Abant, 1999. Disponível em http://www.unicamp.br/aba/boletins/b31/b31_05.htm - Acesso em 28/08/06.

MORIN, Edgar. O Método - A natureza da Natureza. Portugal: Publicações Europa América, 1980.

RIBEIRO, José da Silva. "Jean Rouch - Filme etnográfico e Antropologia Visual". In: Doc On-line, n.3. Covilhã: UBI; Campinas: UNICAMP, 2007. p. 6-54. Disponível em: www.doc.ubi.pt

ROHLING, Jurandir Hillmann et al. "Produção de Filmes Didáticos de Curta Metragem e CD-ROMs para o Ensino de Física". In: Revista Brasileira de Ensino de Física, v.24, n.2, junho 2002. São Paulo: SBF, 2002. p. 168-175.

Recebido em: 30/10/2012

Aprovado em: 21/12/2012 